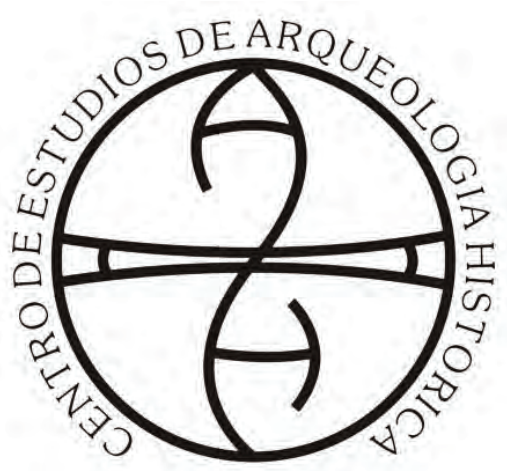

Centro de Estudios de Arqueología Histórica

Universidad Nacional de Rosario

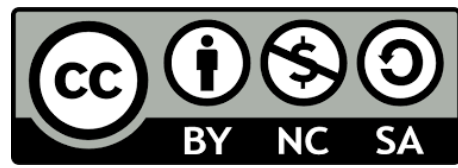

Teoría y Práctica de la Arqueología Histórica

Latinoamericana | Año IX, Volumen 10 | 2020

Revista del Centro de Estudios de Arqueología Histórica, Facultad de Humanidades y Artes,

Universidad Nacional de Rosario

https://teoriaypracticaah.unr.edu.ar/index.php/index

https://rephip.unr.edu.ar/handle/2133/14804

ISSN en línea: 2591-2801

ISSN versión impresa: 2250-866X

Atribución-NoComercial-CompartirIgual 4.0 Internacional (CC BY-NC-SA 4.0)

https://creativecommons.org/licenses/by-nc-sa/4.0/deed.es

Fernando Oliva (ID.: https://orcid.org/0000-0002-1171-

264X) y María Cecilia Panizza (ID.: https://orcid.org/00000001-8283-7231). La Zanja de Alsina y los fortines asociados en los sectores centro y sur del área ecotonal húmedo seca pampeana

\title{
LA ZaNJA de Alsina y los FORTINes ASOCIADOS EN LOS SECTORES CENTRO Y SUR DEL ÁREA ECOTONAL HÚMEDO SECA PAMPEANA
}

\section{THE Alsina's ZANJA AND ASSOCIATED FORTS IN THE CENTRAL AND SOUTHERN SECTORS OF THE PAMPEAN DRY WET ECOTONAL AREA}

\author{
Fernando Oliva* y María Cecilia Panizza**
}

\begin{abstract}
Resumen
En este trabajo se desarrolla un análisis espacial de la Zanja propuesta por el ministro de Guerra Adolfo Alsina, a partir de la comparación de las imágenes satelitales, la cartografía histórica y otras fuentes documentales con el proyecto original y los restos arqueológicos visibles actualmente. El plan estatal buscaba ocupar $56000 \mathrm{~km}^{2}$ del territorio en poder de los indígenas y lograr la reducción de la línea defensiva, la economía de fortines, la extensión de la red telegráfica y la desmoralización de los indígenas al perder sus aguadas principales. En el lapso 1876-1877 se construyó una zanja de 374 km, se instalaron fortines a distancia regular y se fundaron poblados estables (Carhué, Guaminí, Puan y Trenque Lauquen). Mediante la presente investigación se evalúan las trazas materiales generadas por este proyecto y sus

* Centro de Estudios Arqueológicos Regionales (CEAR), Facultad de Humanidades y Artes, Universidad Nacional de Rosario (FHumyAr-UNR); Laboratorio de Análisis Cerámico, Facultad de Ciencias Naturales y Museo, Universidad Nacional de La Plata (FCNyM -UNLP). fwpoliva@gmail.com

** Becaria Post-Doctoral Consejo Nacional de Investigaciones Científicas y Técnicas (CONICET), Centro de Estudios Arqueológicos Regionales (CEAR), Facultad de Humanidades y Artes, Universidad Nacional de Rosario (FHumyAr-UNR); Laboratorio de Análisis Cerámico, Facultad de Ciencias Naturales y Museo, Universidad Nacional de La Plata (FCNyM UNLP).mcpanizza@yahoo.com.ar
\end{abstract}

La Zanja de Alsina y los fortines asociados en los sectores centro y sur del área F. Oliva y M.C. PANIZZA ecotonal húmedo seca pampeana 
características en el área de estudio, considerando como unidades operativas la zanja y paredón junto con los fortines asociados.

Palabras clave: frontera, fortines, Siglo XIX, ecotono, zanja

\begin{abstract}
In this work a spatial analysis of the Zanja proposed by the Minister of War Adolfo Alsina is developed, based on the comparison of satellite images, historical cartography and other documentary sources with the original project and the remains of the archaeological sites currently visible. The state plan sought to occupy $56000 \mathrm{~km}^{2}$ of the territory held by the indigenous people and achieve the reduction of the defensive line, the forts economy, the extension of the telegraph network and the demoralization of the indigenous by losing their main water. In the period 1876-1877 a $374 \mathrm{~km}$ ditch was built, forts were installed at regular distance and stable villages were founded (Carhué, Guaminí, Puan and Trenque Lauquen). This research evaluates the material traces generated by this project and their characteristics in the study area are evaluated, considering as operational units the trench and walling together with the associated forts.
\end{abstract}

Keywords: border, forts, XIX Century, ecotone, ditch

\title{
Introducción
}

En el marco del proyecto acreditado en la Universidad Nacional de Rosario "HUM 525 Arqueología histórica en el área del Sistema Serrano de Ventania y su llanura adyacente”, desde el año 2015 se implementaron actividades sistemáticas de investigación orientadas al registro arqueológico histórico, especialmente al producido durante el siglo XIX (Oliva y Panizza, 2018). En esta oportunidad, se aborda la construcción de la llamada Zanja de Alsina, dado que gran parte de su trazado se desarrolló en el ecotono bonaerense, donde actualmente el equipo del Centro de Estudios Arqueológicos Regionales (CEAR) realiza sus investigaciones. Por lo tanto este trabajo se propone profundizar en el conocimiento de este evento trascendente para la ocupación del territorio e identificar las trazas materiales de aquel proyecto colonizador que, todavía hoy, subsisten en el paisaje, al mismo tiempo que determinar las particularidades que pudo haber adquirido en los distintos sectores del ecotono.

Como antecedentes recientes de trabajos enfocados en la Zanja de Alsina, pueden mencionarse el trabajo de Oliva Gerstner (2010), quien desde un enfoque combinado de Antropología y Geografía buscó mostrar la complementariedad entre las imágenes de Google Earth y los materiales gráficos procedentes de museos virtuales argentinos, a partir del análisis de la construcción de la llamada popularmente "Zanja de Alsina" entre 1876 y 1879; y el trabajo de Landa y colaboradores (2017), quienes a través de un enfoque interdisciplinario, llevaron a cabo análisis espaciales para localizar la zanja y los asentamientos militares adyacentes en el noreste de La Pampa mediante imágenes satelitales, cartografía histórica, fuentes documentales y labor arqueológica. Como antecedente previo de dichas publicaciones, es necesario mencionar el Congreso Nacional de Historia Sobre la Conquista del Desierto, realizado en el Centenario de la campaña de Julio A. Roca, en el año 1979 en General Roca (provincia de Río Negro); los trabajos presentados en dicho evento fueron editados en cuatro grandes tomos (Academia Nacional de la Historia, 1980). Entre los temas desarrollados, por lo menos doce artículos abordaron directamente la figura política de Alsina y/o la zanja que proyectó, los trabajos restantes los mencionaban en mayor o menor medida.

Específicamente el presente trabajo se restringe espacialmente a los sectores central y sur del Área Ecotonal Húmedo Seca Pampeana (AEHSP) de la provincia de Buenos Aires y temporalmente al breve 
lapso de 1876-1878, que fue el momento en que se diseñó y ejecutó la construcción de la Zanja. Se compara el proyecto original con las trazas materiales que se observan en la actualidad en el área de estudio, considerando que la apropiación e identificación con ese pasado de frontera forma parte de la elaboración de la memoria e identidad de las comunidades locales.

\section{EI AEHSP durante el período de contacto hispano-indígena}

El Área Ecotonal Húmedo-Seca Pampeana (AEHSP) consiste en una franja de límites fluctuantes, localizada en inmediaciones del meridiano $62^{\circ}$ de longitud oeste, entre los $39^{\circ}$ y $33^{\circ}$ de latitud sur (Oliva, 2006). El paisaje atraviesa una serie de cambios constantes (variables climáticas y modificaciones en la distribución de las especies animales y vegetales), con la consecuente disminución o ampliación del área en diferentes momentos del Holoceno. Este ecotono constituye una zona de transición entre dos sistemas ecológicos adyacentes (la Pampa Húmeda y la Pampa Seca), y se caracteriza por la presencia de especies del espinal, como el caldén (Prosopis caldenia), el chañar (Geoffroea decorticans) y el algarrobo (Prosopis nigra), entre otros. Además, se distingue por una alta disponibilidad de agua, por una variabilidad mayor de recursos respecto a las zonas circundantes, y por una alta concentración de nutrientes biológicos y de recursos minerales. En este espacio se identifican accidentes topográficos estables como el Sistema Serrano de Ventania, o grandes cuerpos de agua permanentes (Lagunas Las Tunas Grandes, del Monte, Los Chilenos, de Puan, Las Encadenadas, entre otros), que habrían constituido focos de asentamiento o hitos visuales para circular por el territorio. De acuerdo a sus características ecológicas, se considera una subdivisión en tres sectores del AEHSP: norte, central y sur (Oliva y Panizza, 2015). Este trabajo se ocupa de los sectores central y sur, donde se relevaron los vestigios de la zanja histórica, correspondientes a los actuales municipios de Rivadavia, Trenque Lauquen, Guaminí, Adolfo Alsina, Puan, Saavedra y Tornquist (Figura 1).

El sector central, desde el noroeste de la provincia de Buenos Aires por el norte hasta las lagunas Encadenadas del Oeste en el sur, se caracteriza por la ausencia de afloramientos rocosos de importancia, y la presencia de un conjunto de lagunas encadenadas (Lagunas de Epecuen, Arroyo Venado, del Monte y Alsina), conformando un lugar atractivo para las sociedades cazadoras-recolectoras. En cambio, el sector sur se diferencia por la presencia del Sistema Serrano de Ventania y su llanura adyacente, donde se concentran recursos críticos como fuentes de materias primas líticas, agua potable, entre otros; con un número importante de abras y valles que conectan las diferentes secciones serranas entre sí y con las llanuras circundantes. Estas sierras están conformadas por cuarcitas, areniscas y limolitas, afectadas por un fuerte plegamiento carente de fracturación asociada, que dio lugar a numerosas cuevas; en tanto en el sector pedemontano hay afloramientos de rocas graníticas y riolíticas, además de contar con un sistema hídrico constituido por múltiples cuerpos y cursos fluviales (Oliva y Panizza, 2015).

En el momento de contacto hispano-indígena el AEHSP fue un área de transición entre las nuevas poblaciones europeas (y sus descendientes) y las poblaciones indígenas locales, constituyendo un lugar de pasaje para acceder a otros sitios, entre los cuales pueden mencionarse las Salinas Grandes, descubiertas en 1668 por la sociedad de origen europeo (Taruselli, 2005-2006, p. 128). Posteriormente las Salinas Grandes se convertirán en un punto de interés para la organización de expediciones con el objetivo de acopiarse de sal, mediante la extracción y el transporte del producto hacia la ciudad de Buenos Aires. Estos viajes se realizaron en los años de 1759, 1774, 1778, 1786, 1791, 1793, 1798, 1800, 1803, 1804 y 1805; estas incursiones en territorio indígena eran aprovechadas para organizar reuniones, consejos y otros tipos de encuentros entre los hispano-criollos y los líderes de las diversas parcialidades indígenas,

La Zanja de Alsina y los fortines asociados en los sectores centro y sur del área

F. Oliva y M.C. PanizZA ecotonal húmedo seca pampeana

Páginas 59-80 
con el fin de establecer tratados o alianzas, y de efectuar intercambios de regalos y otros recursos (ver en García, 1969 [1810], [1822]; Zizur, 1972 [1786], entre otros).

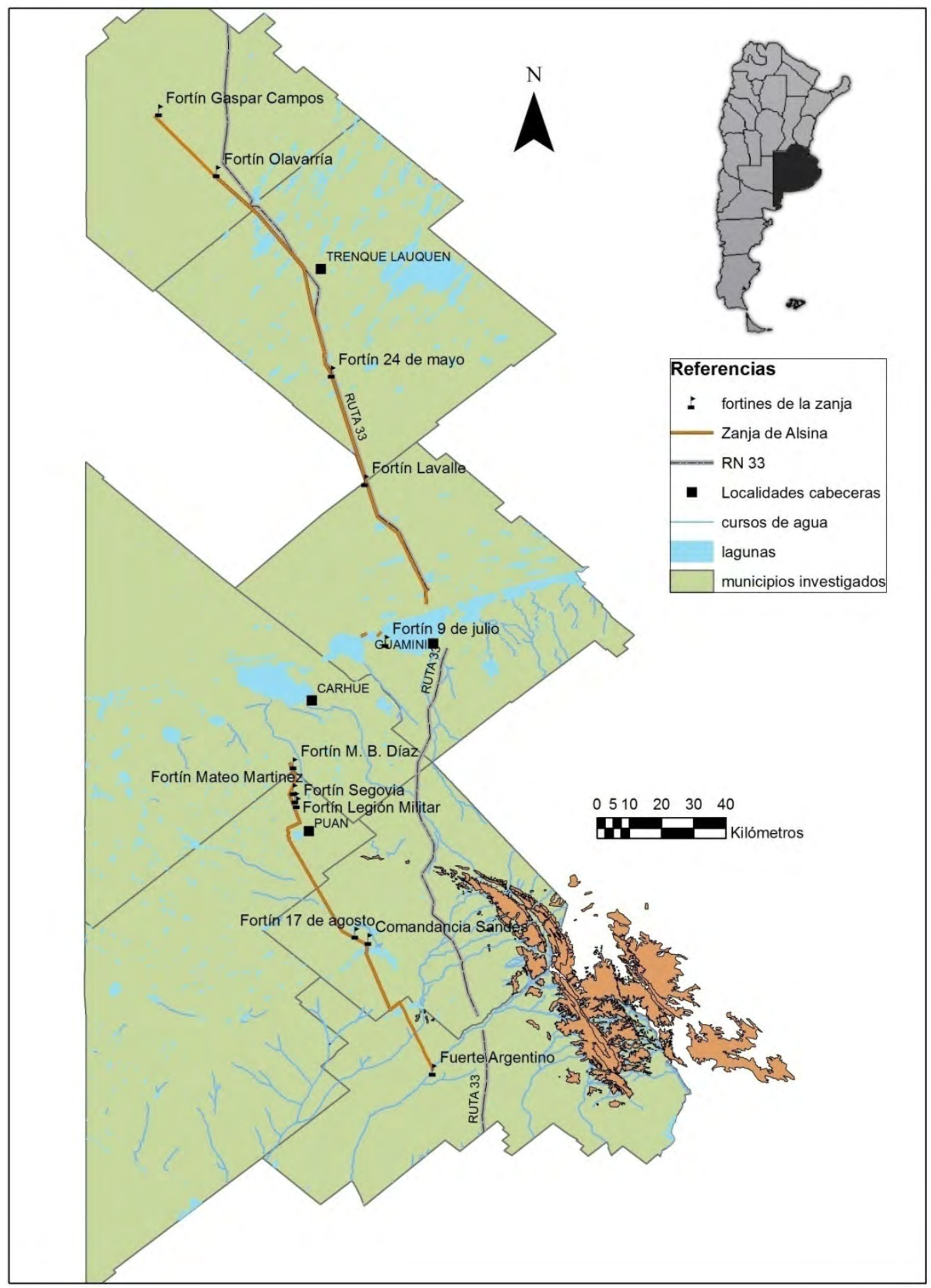

Figura 1. Mapa de los municipios de la provincia de Buenos Aires abarcado en nuestras investigaciones, correspondientes al Área Ecotonal Húmedo Seca Pampeana, con la ubicación de algunos fortines mencionados en el texto. La línea de la Zanja de Alsina se encuentra señalada en color marrón. 
En este momento, las sierras de Ventania aparecen mencionadas en los documentos como lugar de asentamiento indígena, los caminos utilizados por las expediciones pasaban al norte de estas serranías y bordeaban las lagunas Encadenadas. Algunas de las cuales conservan su nombre, como L. del Monte, otras sufrieron leves modificaciones, L. de los Paraguayos a L. La Paraguaya, mientras otras eran conocida por otras denominaciones, como L. San Lucas actualmente L. Epecuén; (ver Zizur, 1786a, 1786b; entre otros).

La información de este período se vincula a los diarios sobre los viajes a Salinas, entre los cuales se destacan los escritos por el piloto de la Real Armada Pablo Zizur en 1786 (Zizur, 1972 [1786]) y por el coronel Pedro Andrés García, a quien la Primera Junta le encomendó la expedición anual de 1810 (García, 1969 [1810]). Estas expediciones permitían recabar datos sobre las características ambientales del entorno, los grupos indígenas de la región, sus líderes o caciques, sus movimientos a través del paisaje, la cantidad de tolderías, guerreros y ganado que poseían, entre otros.

Específicamente sobre el área de Ventania, los antecedentes documentales más relevantes comienzan a aparecer a partir del siglo XVIII. En 1742 los españoles realizaron los primeros tratados de paz en el "Casuhati" con los grupos serranos, según el relato del misionero José Sánchez Labrador (1936 [1772]). Luego, en 1770 se produce la expedición de Hernández al sur de Sierra de la Ventana (Hernández, 1969 [1770]). En 1781 las autoridades envían a Zizur para negociar con Lorenzo Calpisqui (el cacique principal de la zona) el canje de prisioneros por cautivos y el establecimiento de las paces, además de inspeccionar la campaña. En el siglo XIX, cuando la comitiva de García se dirigía a Salinas Grandes, atravesaron la zona de Ventania al norte de las sierras, permaneciendo cinco días en el lugar (García, 1969 [1810]). En cambio, en 1822, el viaje de García estuvo específicamente orientado a Sierra de la Ventana, con el fin de establecer paces permanentes con los caciques principales. Posteriormente se producen eventos más conflictivos, como las campañas de Rodríguez en 1824, de Rauch en 1826 y de Rosas en 1833 (Barros, 1872; Comando General Del Ejército, 1974; Garretón, 1946; Pueyrredón, 1929; Saldías, 1892); las batallas de Pigüé en 1858 y de Cura-Malal Chico en 1877 (Monferran Monferran, 1958, 1962), entre otros. Ese último año es cuando se comienza a construir la Zanja de Alsina y los asentamientos asociados a su trazado, como preludio de la estrategia ofensiva desarrollada por Roca en 1879, que culmina en lo que actualmente se considera un genocidio indígena (Delrio et al., 2010; Pérez, 2011; Vezub, 2011).

\section{El proyecto de Alsina}

En primer lugar se presenta un esbozo de la personalidad del ideólogo de la zanja, luego los antecedentes relevantes de este proyecto, y finalmente las características que asumió la construcción de esta obra. La semblanza del personaje histórico sintetiza los datos vertidos por diversas fuentes bibliográficas (Gamboni, 1994; Ramayón, 1930; Sánchez, 1878; Yaben, 1938-1940; entre otros).

Adolfo Alsina fue un político y jurisconsulto argentino que nació en Buenos Aires el 4 de enero de 1829. Era hijo del jurista y político unitario Valentín Alsina y de Antonia Maza (hija del abogado y político federal Manuel Vicente Maza). En 1835, durante la segunda gobernación de Rosas en Buenos Aires, su familia tuvo que trasladarse a Montevideo donde inició sus estudios de Derecho, que finalizó obteniendo el título de doctor en Jurisprudencia en su ciudad natal, a la cual regresó en 1852, luego de la batalla de Caseros. Participó en el ejército unitario durante la guerra civil, estuvo en las batallas de Cepeda y de Pavón. En 1862 fue elegido diputado al Congreso, donde se opuso a la federalización de la provincia de Buenos Aires, tema que ocasionó la división del partido en dos: Autonomista (dirigido 
por él) y Nacionalista (manejado por su adversario Bartolomé Mitre). Otros cargos políticos importantes que detentó fueron el de gobernador de la provincia de Buenos Aires en 1866, de vicepresidente de la República en la presidencia de Sarmiento (1868 - 1874), y finalmente el de ministro de Guerra y Marina durante la presidencia del doctor Avellaneda. En el marco de este último cargo, para solucionar "el problema indígena" elaboró un proyecto que consistía en una línea de fortines protegidos por una zanja, plan que no implicaba el exterminio de los "indios". Mientras inspeccionaba los trabajos en la línea de frontera, cayó gravemente enfermo en Carhué, desde donde fue trasladado a Buenos Aires, falleciendo el 29 de diciembre de 1877.

\section{Antecedentes de la Zanja}

El contexto previo de la construcción de la zanja corresponde a un incremento de los malones e incursiones indígenas que se produjo a comienzos de la década de 1870, entre los cuales destaca el ataque efectuado en 1872. Bajo la dirección de Calfucurá, seis mil "indios de lanza” avanzaron sobre los pueblos de General Alvear, 25 de Mayo y Nueve de Julio. El resultado de esta incursión fue la muerte de 300 cristianos y el arreo de unas 200000 cabezas de ganado (Walther, 1980, p. 352). Como respuesta, se produjo el combate de San Carlos, próximo al fuerte homónimo (en el actual partido de Bolívar), con el triunfo de las tropas nacionales (Walther, 1980). A fines de 1873 Namuncurá organizó una invasión por las zonas del fuerte General San Martín y de Pillahuincó, obteniendo unas 1000 vacas y 100 caballos; pero los reprimieron y abandonaron arreo y cautivos (Walther, 1980, p. 368). Posteriormente, en diciembre de 1875 se inició el "Malón Grande", que tuvo como saldo 500 cautivos y aproximadamente 300000 reses de los partidos de Azul, Tandil, Olavarría, Juárez, Tapalqué, Tres Arroyos y Alvear (Walther, 1980, p. 384). En marzo de 1876, los indios fueron enfrentados y vencidos en la batalla de Paragüil.

La difusión de estos eventos en los medios alimentaba el imaginario social de la época, en el cual predominaba una visión de los indígenas que los caracterizaba negativamente (sucios, perversos, crueles, lascivos, bárbaros, incivilizados, nómades refractarios a la civilización) y los asociaba a ideas de destrucción, invasión, saqueo, depredación de haciendas, robo de ganado, malones, que despertaban sensaciones de horror y pánico en las poblaciones, como queda reflejado en los escritos de la época (Quijada, 1999, 2003).Para detener este tipo de avanzadas indígenas, anteriormente se habían desarrollado obras similares a la Zanja propuesta por Adolfo Alsina. Al sur de la provincia de Buenos Aires, en la primera mitad del siglo XIX se puede mencionar la construcción de dos zanjas y de cuatro fortines para proteger de los ataques indígenas a la población y hacienda de la Fortaleza Protectora Argentina en Bahía Blanca (Thill y Puig Domenech, 2003, pp. 98-99), en el marco de la campaña dirigida por Juan Manuel de Rosas (1833). Las estructuras remanentes de la zanja de Rosas y del fortín La Catalina fueron recientemente relevadas e investigadas (Tomassini y Vecchi, 2015). Por otra parte, al norte de Santa Fe se habría realizado una "zanja de López" (por el brigadier general Estanislao López), con una intención similar; y se comenta que de esta obra habría tomado Adolfo Alsina la idea de la zanja (Sánchez Zinny, 2010).

\section{La Zanja de Alsina}

En 1874 el presidente Nicolás Avellaneda designó a Adolfo Alsina como Ministro de Guerra y Marina. Como el gobierno estaba interesado tanto en solucionar "el problema del indio" como en extender la frontera desde el río Salado hasta el río Negro, con el objetivo de anexar tierras para integrarlas a la producción económica; el ministro de Guerra elaboró un plan basado en un sistema de fosas y fortifica- 
ciones (Alsina, 1877), que serían instaladas desde Nueva Roma (en el sudoeste de la provincia de Buenos Aires) hasta la zona de La Amarga (en el sur de la provincia de Córdoba). A partir de entonces fue conocida como la "Zanja de Alsina", se había diseñado para cubrir 610 kilómetros; pero con gran esfuerzo y en el marco de la crisis económica de la década de 1870 (Panettieri, 1984; Fernández, 2017), entre 1876 y 1877 se construyeron sólo 374 kilómetros para delimitar una nueva frontera, el proyecto quedó trunco al morir Alsina a fines de 1877 (Prado y García Ledesma, 1980). Lo sucedió en el cargo el general Roca, quien se había opuesto al proyecto de la zanja y promovía una ofensiva más agresiva, que efectivizó mediante la conocida "campaña al desierto" de 1879.

El plan de Alsina consistió en erigir fortines al costado de la zanja y con una distancia aproximada de una legua (medida equivalente a cinco kilómetros y medio aproximadamente) para facilitar las comunicaciones entre los asentamientos ante ataques indígenas u otros sucesos. Estas pequeñas fortificaciones dependían de las comandancias militares de Italó, Trenque Lauquen, Carhué, Guaminí y Puan, conectadas mediante el telégrafo (Castillo de Parrillo, 1980). Su construcción, considerada extremadamente costosa y criticada por este motivo, fue dirigida por el ingeniero francés Alfredo Ebelot y en ella trabajaron alrededor de 800 hombres (entre Guardias Nacionales y peones contratados).

La obra presentaba las siguientes características: con la forma de una pirámide invertida, debía tener tres metros de ancho y dos metros de profundidad, con 60 centímetros en la base o fondo, bordeada por un terraplén, paredón o parapeto de un metro de alto por unos cuatro metros y medio de ancho (Gómez, 1980) construido con la tierra extraída de la excavación del foso y reforzado con una empalizada; estas medidas podían varias según la geografía del lugar, en algunos sectores tomó forma de un muro debido a la dureza del terreno (Figura 2). Ebelot (1968, p. 114) refiere que la zanja tenía una longitud de $400 \mathrm{~km}, 2,60 \mathrm{~m}$ de ancho y 1,75 m de profundidad; el ancho del fondo sería de 0,50 m. Internamente el foso contaría con un parapeto de adobes de $1 \mathrm{~m}$ de alto, de la tierra sacada de las excavaciones, cubierto con arbustos espinosos. Donde el suelo presentara rocas duras, la trinchera sería sustituida por un terraplén entre dos muros de adobes (Figura 2).
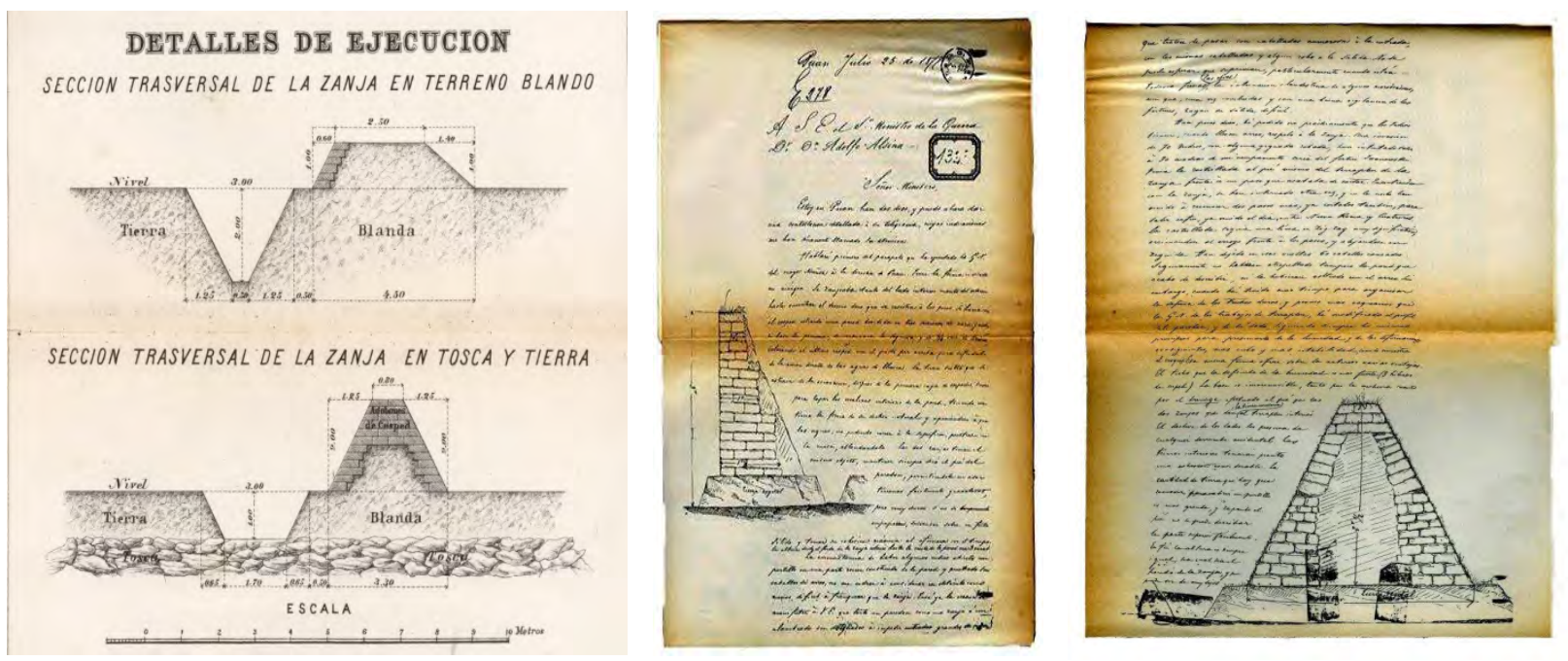

Figura 2. Dibujos de la estructura de la zanja. A) por J. Wysocki (1877). B) por A. Ebelot (en Luzuriaga, 1980). 
Los 109 fortines levantados a la vera de la zanja estaban a cargo de un oficial y de ocho a diez soldados, quienes debían efectuar descubiertas o reconocimientos todos los días para averiguar la localización de los indígenas (Gómez, 1980). Las construcciones presentaban forma circular, de aproximadamente veinte metros de diámetro, con un rancho de adobe y un mangrullo en el centro, rodeados por un foso y un paredón de palos a pique como defensa. En las comandancias se llevaba a cabo el abastecimiento de caballos, la centralización de información proveniente de los fortines vecinos y el establecimiento de los familiares de los soldados.

El ingeniero francés encargado de dirigir la construcción de la zanja, Alfred Ebelot, fue un gran defensor de la utilidad de esta obra (Ebelot, 1968), como quedó reflejado en sus publicaciones en la Revue des Deux Mondes. Utiliza el símil de la muralla china, al que aludían despectivamente los opositores del proyecto como Roca y Olascoaga (Walther, 1980, p. 428; Olascoaga, 1974, p. 51) para ridiculizar la iniciativa (Blengino, 2005), pero Ebelot emplea este referente como un símbolo positivo (Ebelot, 1968, p. 108).

La zanja no pretendía impedir la entrada y salida de los grupos indígenas ni ser una construcción permanente, sino constituir a corto plazo un obstáculo que dificultara los grandes arreos de ganados, robados en las estancias para ser vendidos en Chile; y a largo plazo una línea de base para ejecutar la ofensiva (Alsina, 1877, pp. 128-129), según análisis recientes "una operación ofensiva que simula ser defensiva" (Navarro Floria, 2013). La demora en el paso del ganado daría tiempo a las partidas de soldados para alcanzarlos y recuperar los bienes robados. Sin embargo, las partidas indígenas desarrollaron una estrategia para atravesar la zanja, ingresando numerosas ovejas en un lugar para utilizarlas como puente (Blengino, 2005).

En la actualidad se observan escasas evidencias de la construcción de la zanja y los fortines de esta línea. En cambio, sobre las comandancias se desarrollaron las actuales localidades, cabeceras de sus respectivos distritos, conectadas mediante la Ruta Nacional 33 llamada "Ruta del Desierto Dr. Adolfo Alsina". Esta ruta, que une las ciudades de Rosario (provincia de Santa Fe) al norte y Bahía Blanca (provincia de Buenos Aires) al sur, se ubica de forma paralela a pocos metros de la traza de la Zanja de Alsina (Nagy, 2013).

\section{Los logros de Alsina}

Como fue mencionado previamente, la estrategia de Adolfo Alsina ha sido considerada tradicionalmente como "defensiva" en contraposición a la política "ofensiva" que Julio A. Roca promovía y que ejecutó posteriormente cuando ocupó el cargo de ministro de Guerra, a la muerte de Alsina. Ramírez Juárez atribuye esta idea a una "mala interpretación" del proyecto de Alsina que "se generalizó", el mismo Alsina rechazó que su intención fuera meramente defensiva (Ramírez Juárez, 1946, p. 135). En este sentido, debe considerarse que los logros de la campaña de Roca se basan en la eficacia de la política desarrollada por Alsina. Ramírez Juárez (1946, p. 145) sostuvo que "El proyecto del doctor Alsina fue magnífico en su ejecución y concepción..." La estrategia "defensiva" de Alsina logró la incorporación de más de cincuenta y seis mil kilómetros cuadrados de tierras al control del gobierno nacional para dedicarlos a la ganadería y la agricultura, privó a los indígenas del acceso a pasturas y aguadas en parajes relevantes estratégicamente; produjo el asentamiento del ejército en diferentes puntos de la nueva línea de frontera, la extensión de la red telegráfica que aseguró las comunicaciones, la fundación de pueblos (que subsisten actualmente como localidades y cabeceras de partido) y el conocimiento de un nuevo territorio mediante la exploración y relevamiento científico (Arce, 1980; Castillo de Parrilo, 1980; Debenedetti, 1980; Walther, 1980).

La Zanja de Alsina y los fortines asociados en los sectores centro y sur del área F. Oliva y M.C. PanizZA ecotonal húmedo seca pampeana 
Teoría y Práctica de la Arqueología Histórica Latinoamericana

Año IX, Volumen 10 | 2020 / ISSN en línea: 2591-2801 | ISSN versión impresa: 2250-866X

\section{La obra de la Zanja en el AEHSP}

Los sectores del Área Ecotonal Húmedo Seca Pampeana ocupados por la zanja de Alsina y los fortines asociados corresponden a lugares que poseían un valor estratégico en el circuito de movilidad de los grupos indígenas, donde se localizaban las aguadas y pasturas permanentes (Landa et al., 2017; Ebelot, 1968), en las zonas de Carhué, Puán, Guaminí y Trenque Lauquen. El diseño y la construcción de la zanja contaron con la participación de profesionales (Federico Melchert, Alfredo Ebelot y Jordan Wysocki en el área de nuestro estudio) que, además de intervenir en la elección de los lugares y las decisiones vinculadas a la "Zanja de Alsina" y a los fortines, aportaron información importante mediante el levantamiento de planos, los informes elevados, la descripción y la localización de rastrilladas, rasgos geográficos (montes, lagunas, médanos, entre otros) y otros datos topográficos destacables (Orga, 2010).

La zanja y el parapeto como rasgo del paisaje fue un elemento de referencia ampliamente utilizado por los agrimensores que realizaron las primeras mensuras de los terrenos de los partidos involucrados, junto con la presencia de los restos de los fortines (generalmente identificados con sus nombres), el camino paralelo que unía los fortines al este de la zanja, los potreros y los corrales. Las trazas materiales de la zanja, observables en la actualidad en el área de estudio, se encuentran vinculados a tramos de la ruta (nacional 33) o caminos vecinales y a los vestigios de los fortines ubicados a la vera de la zanja que han podido ser localizados. Por la limitación de espacio, se refieren los casos más relevantes por municipio, localizados en el transcurso de esta investigación. Al mismo tiempo, el estudio está en proceso y todavía resta acceder a algunos tramos del trazado de la zanja, por la dificultad que representa que la mayoría del terreno afectado se ubique en propiedad privada. Por lo tanto, no se descarta que nuevos hallazgos se produzcan en el futuro con el avance de las tareas propuestas.

En el partido de Rivadavia se han identificado la presencia de catorce fortines junto a la Zanja de Alsina. En 1880 el agrimensor Luis Silveyra, enviado por el gobierno, realiza una mensura de la zona (lote 16) donde figuran la ubicación de los fortines de la línea y el trazado de la zanja (Archivo Histórico de Geodesia de la Provincia de Buenos Aires, en adelante AHG, mensura $\mathrm{n}^{\mathrm{o}} 2$ del partido de Rivadavia). En 1882 el agrimensor Juan Alsina hizo la mensura de la subdivisión del lote 16, donde se mantiene la localización de los fortines y la zanja paralela a la línea de unión de los fortines, y se presenta el proyecto del pueblo para Fortín Olavarría (AHG, mensura $n^{\circ} 4$ del partido de Rivadavia), erigido entre las comandancias de Trenque Lauquen e Italó. La localidad se ubica en el Partido de Rivadavia, en el km 364 de la Ruta Nacional 33 a 27 km al sur de la ciudad de América. En la mensura no 46 del año 1897 (AHG) aparece marcado el fortín y las primeras construcciones del pueblo casa de negocios de Francisco Gorchs, al costado de la traza de la zanja. Se considera el año 1901 como la fecha fundacional del pueblo por haberse realizado el primer loteo de los terrenos (Orga, 2010). Hay una réplica del fortín en la localidad.

Otro fortín situado en la línea derecha, sobre la zanja de Alsina, es el denominada Gaspar Campos, en las mensuras no 18 y 23 de Rivadavia correspondientes a los años de 1889 y 1891(AHG) se ubica dentro de la propiedad de Mauricio Duva. Próximo a los restos del fortín (a menos de 1000 metros) se desarrolló el pueblo de San Mauricio a partir de una pulpería (mensura $n^{\circ} 18$ ) fundado en 1884 . En la mensura no 33 del año 1894 (AHG) no aparece marcado el fortín Gaspar Campos en la propiedad de Duva, pero si están indicados otros fortines de la línea y la zanja, denominada Zanja Nacional en la diligencia de mensura (y en otras mensuras del partido), la cual es tomada como referencia para las medidas por el agrimensor. En las mensuras n 44 y 45 de 1897 (AHG) tampoco aparece la ubicación del fortín Gaspar Campos (en cambio si aparecen los emplazamientos de Villalón y la de Martínez de Hoz), y se

La Zanja de Alsina y los fortines asociados en los sectores centro y sur del área

F. Oliva y M.C. PanizZA ecotonal húmedo seca pampeana

Páginas 59-80 
indica la presencia de la pulpería, la capilla y otras construcciones en la propiedad de Duva. Mediante decreto municipal n 197/84, se declaró a San Mauricio de Interés Histórico, resaltando que el lugar fue testigo de acontecimientos históricos, su ubicación a la vera de la Zanja de Alsina y el patrimonio que representan las ruinas de los primeros edificios de la localidad, como la Capilla San Mauricio. También posee una réplica del fortín en el pueblo.

Otras mensuras del municipio de Rivadavia donde se observa ambos rasgos, el trazado de la zanja y el emplazamiento de fortines, son las $n^{0}$ 1, 3, 13 (Figura 3A), 34, 35, 36 (AHG). En planos de otras mensuras (AHG, $n^{\circ} 25$ y 27) no aparece la zanja marcada pero si se destaca la presencia del camino de Trenque Lauquen a Italó, que corría paralelo al este de la zanja y de los fortines, y se encuentra mencionado en otras mensuras. En la mensura n ${ }^{\circ} 24$ se menciona el terraplén de la zanja, sobre el cual el agrimensor coloca los mojones y reparte el espacio entre el borde de la zanja y el terraplén para posteriormente ser alambrado. Todavía en el año 1902 se menciona a la zanja y su parapeto en la mensura $n^{\circ} 48$, y en la Hoja 3563-27-4 San Mauricio de la Carta Topográfica de la República Argentina levantada en el año 1952 figura el Camino de la Zanja.

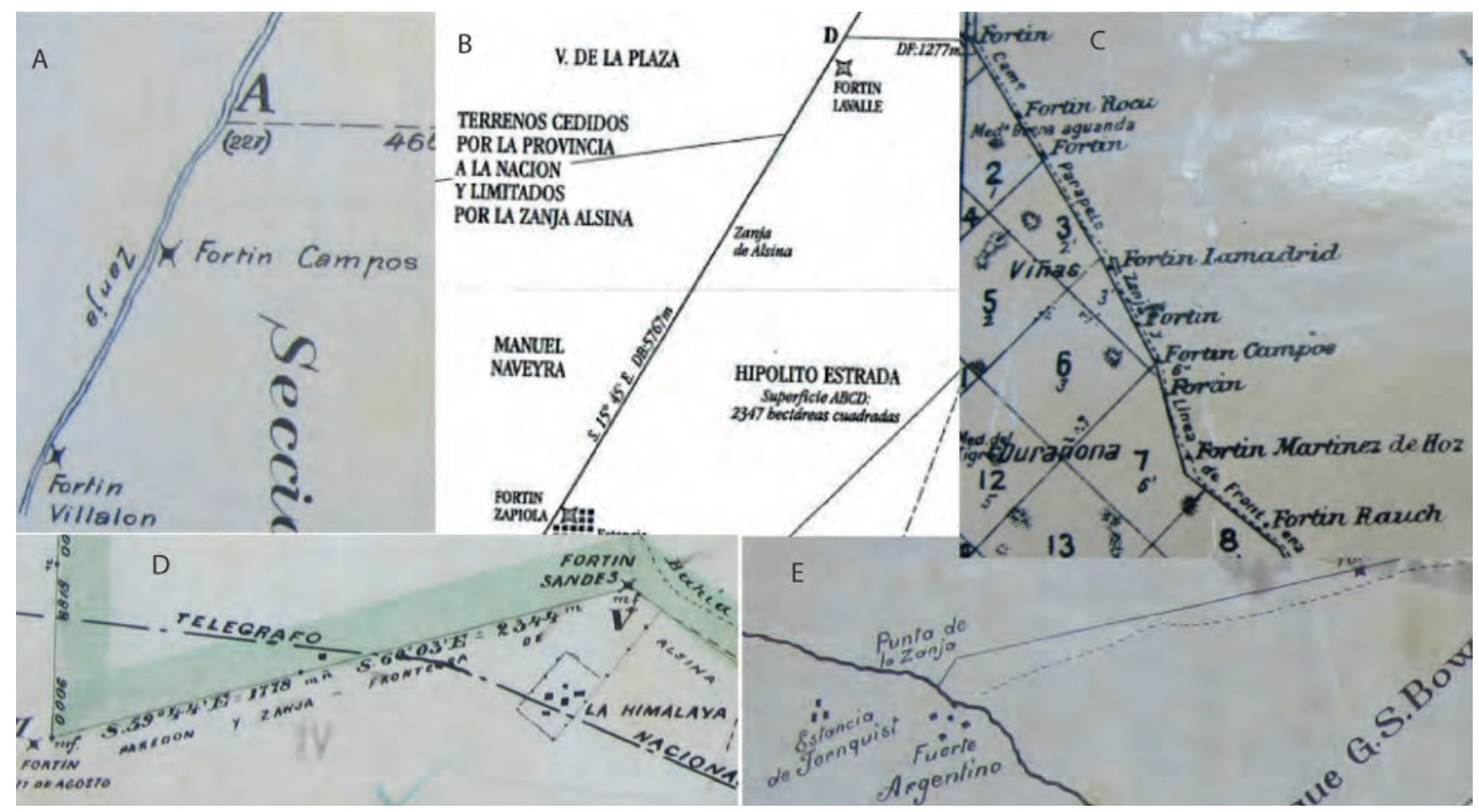

Figura 3. La Zanja representada en distintas fuentes cartográficas (depositadas en el Archivo Histórico de Geodesia de la provincia de Buenos Aires). A) Detalle de Mensura $n^{\circ} 13$ de Rivadavia. B) Detalle de Mensura $n^{\circ} 76$ de Guaminí. C) Detalle del plano de National Territories. Names of land-owners. D) Detalle de la Mensura ${ }^{\circ} 41$ de Saavedra. E) Detalle del plano de la sección XIX.

En el partido de Trenque Lauquen, entre la veintena de fortines asociados a la zanja, se destaca la comandancia que originó a la actual localidad cabecera del distrito. Dicha ciudad posee dos instituciones vinculadas al avance estatal y a las campañas militares del siglo XIX, uno es el Museo de la Comandancia y el otro es el Museo Histórico Regional, próximo al cual se ha levantado una réplica de fortín, 
llamado "12 de abril" en honor a la fecha de fundación de la localidad, en el parque municipal. La construcción de la comandancia militar sobre la cual se fundó el pueblo en 1876, ha sido conservada en el interior del Palacio Municipal y ha sido declarada Monumento Histórico Nacional por decreto $\mathrm{n}^{\mathrm{o}} 4452$ en el año 1958. Además, en Trenque Lauquen se ha organizado en 1965 el evento denominado la Semana Nacional de la Conquista del Desierto, el cual se ha repetido en numerosas oportunidades (Nagy, 2008). Por otra parte, una localidad del partido, La Zanja, recuerda con su nombre la obra que mandó realizar Adolfo Alsina para contener el avance de los malones indios, pero su fundación es posterior a la misma (1897) y está ligada a la llegada del ferrocarril.

Con respecto a los espacios públicos, debe señalarse el cartel con la leyenda "aquí cruzó la Zanja de Alsina frontera de la civilización - año 1876", ubicado sobre la Ruta Nacional 5 a 2,5 kilómetros al oeste de la rotonda del cruce de la Ruta Nacional 33 que une Rosario con Bahía Blanca. En el lugar del cruce de la zanja se observa un monolito, que data de 1947, donde en una de sus caras presenta un mapa de la provincia de Buenos Aires, con la traza de la zanja marcada y la indicación de algunos lugares importantes vinculados (Bahía Blanca, Puan, Carhué, Guaminí, Trenque Lauquen e Italó) y el punto donde se encuentra el viajero. Por encima del mapa, hay un escudo con una atalaya en el centro de la corona. Por debajo, la siguiente leyenda: "Traza de la Zanja de Alsina $550 \mathrm{~km}$ cavados con pala en 1877 por el Ejército en la guerra contra las tribus. Coordinación Museos T. Lauquen”. En otra cara se observa un plano de la traza de la zanja, destacando como atraviesa el partido de Trenque Lauquen, con el mismo escudo en el extremo superior de la pared, y una leyenda en el extremo inferior: "aquí cruzó la Zanja de Alsina frontera de la civilización en 187613 de abril de 1946". El mismo mensaje acompaña la réplica del mangrullo de un fortín sobre la ruta nacional 33 en el km 308.5: “Aquí se alzó en 1876 el fortín 24 de mayo frontera de la civilización".

Desde el lugar donde se ubica el monolito previamente mencionado, un camino de tierra atraviesa la ruta 5, el cual hacia el sur transita sobre el lado oeste de la traza de la zanja, observándose montículos de tierra del lado este y una pequeña cañada que se supone son los restos de la zanja. Este camino es la antigua traza de la ruta 33, aproximadamente tres kilómetros hacia el sur el camino cruza la traza de la zanja y continúa sobre el lado este aproximadamente siete kilómetros más hasta empalmar con la actual traza de la ruta 33. Desde ese punto, hacia el sur sigue la ruta 33 superpuesta a la traza de la zanja. Debe destacarse que hay algunos tramos de la ruta que se separan de la zanja, como el ejemplo mencionado, para sortear determinados rasgos geográficos del paisaje, como los bañados.

En Argentina, el historiador José F. Mayo fue el primero en utilizar el relevamiento aéreo y la fotografía aérea para una aplicación científica, en este caso para reconocer y fotografiar, a la luz crepuscular, la línea de fortines y rastrilladas indígenas desde Trenque Lauquen a Guaminí (González 1952a, 1952b). Desde una avioneta en 1951, realizó fotografías de determinados tramos y ubicó los montículos donde habrían estado emplazados los fortines. Posteriormente, en el año 2006, los aficionados Juan José Estévez y Ariel Grub llevaron a cabo un relevamiento de los fortines y de la Zanja de Alsina de la Frontera Norte, registrando su ubicación en el terreno con un GPS, las coordenadas obtenidas fueron trasladadas a una imagen satelital. Estas actividades se enmarcan dentro de la continuidad de la construcción de un relato promovido por la historia tradicional de la ciudad de Trenque Lauquen, desde los historiadores locales (Mayo, 2003; Estévez, 2000; entre otros), como Mayo y Estévez (Nagy, 2013). Actividades parecidaspor parte de historiadores locales, incluyendo la identificación de sitios y la colocación de monolitos recordatorios, han sido registradas en otros municipios del ecotono bonaerense, como Puan (Michelutti, 2009), y en el noreste de la provincia de La Pampa durante la década de 1980 (Caccia, 2004).

Con respecto a la información brindada por las mensuras (Figura 3), es destacable los datos que 
aportan acerca del paisaje (médanos, jagüeles, bañados, aguadas, vegetación, entre otros), los primeros establecimientos (pulperías, puestos, estancias, entre otros), distancias, caminos, línea telegráfica, ubicación de fortines y la traza de la zanja de Alsina (ver entre otras, AHG, mensuras nº 4, 16, 32, 89 y 104 de Trenque Lauquen).

En los partidos de Guaminí y de Adolfo Alsina se observa que la zanja se interrumpe en varios trechos próximos a la zona de las lagunas Encadenadas. Tanto Guaminí como Carhué tenían como rasgo valioso para el proyecto defensivo su cercanía a fuentes de agua como las grandes lagunas. Este sistema lagunar constituyó una barrera natural en la zona, por lo cual la zanja sólo se realizó en dos trechos entra la Laguna del Monte y Laguna Venado. En la actualidad es difícil realizar los relevamientos de la zanja en este sector, debido a las condiciones ambientales por los ciclos de inundación y la realización del canal, ya que alteraron la línea de costa de las lagunas y aumentaron el caudal de agua (Miraglia, 2010; Montesarchio, 1990).

En el partido de Guaminí, la Ruta Nacional 33 sigue un recorrido paralelo al emplazamiento de la Zanja de Alsina, entre los Fortines Lavalle y Maza (de norte a sur Zapiola, General Conesa, Bravos del 2, General Martínez, Lamadrid, Castelli, Patriotas, Belgrano, Suarez, Rossetti, Paunero, Coronel Rauch, Avellaneda y Casares), tal como se encuentra representado en el plano confeccionado por Wysocki de 1877. Según este plano, el otro trecho en donde se construyó la zanja es el correspondiente al tramo entre los fortines Portela y Barquín. Sin embargo, en la Memoria de Guerra y Marina del año 1878 se informa la construcción de los fortines "9 de Julio" y "25 de Mayo" sobre la zanja entre la laguna del Venado y la laguna del Monte (al norte de la línea que une los fortines Barquín y Portela). Este dato es corroborado en los planos de "National Territories. Names of land-owners" de 1884 (signatura 3115-28-1) y de los “Terrenos de la sección segunda de la provincia de Buenos Aires. Departamento de ingenieros civiles de la República Argentina 1881" (signatura 630-27-4), depositados en el Archivo de Geodesia del Ministerio de Obras Públicas de la Provincia de Buenos Aires. En la orilla sudoeste de la Laguna del Monte se ubicó el campamento que originó la ciudad de Guaminí, actual cabecera del partido homónimo. El decreto $\mathrm{n}^{\mathrm{o}}$ 1983 del Poder Ejecutivo Nacional del año 1983 declaró como lugar histórico el sitio de la comandancia Santa María de Guaminí. Debe destacarse que todavía se mantiene el edificio construido en 1877 con fachada de estilo colonial, donde funcionó la Comandancia de Fronteras Oeste hasta el año 1882, cuando se retiraron las tropas; posteriormente se ubicó el Juzgado de Paz, hasta 1886 que pasa a ser la sede de la Municipalidad hasta 1939, desde ese momento hasta el presente funciona la Comisaría de Policía. Cerca de uno de los balnearios de Guaminí pueden localizarse restos de la Zanja. Además, debe destacarse el caso de la localidad de Garré, que presenta la particularidad de pertenecer a tres distritos (Guaminí, Trenque Lauquen y Tres Lomas), donde puede observarse una réplica del mangrullo del Fortín Lavalle. En el caso de la información brindada por las mensuras (Figura 3B), es similar a lo expuesto previamente en los casos de Rivadavia y Trenque Lauquen.

En el partido de Adolfo Alsina, el tramo que presenta construcción de zanja o parapeto es el correspondiente a los fortines Lomas Valentinas, Morales y Mayor Baldomero Díaz (este último ubicado sobre el Parapeto de Alsina), en lo que se muestra coincidente con la cartografía y las fuentes documentales. En la diligencia de mensura $\mathrm{n}^{\mathrm{o}} 1$ de Puan (AHG, foja 10 cara anterior), se puede observar que el agrimensor Eduardo Castex señaló el comienzo de "la zanja o paredón de la línea de frontera establecida por el Doctor Alsina" a los 1901 metros hacia el sudeste del fortín "Zelaya" (sic), que sería el nombre deformado del fortín Subteniente Zelada. Desde allí, afirma que sigue casi sin interrupción hasta el río Sauce Chico frente a Fuerte Argentino (actual partido de Tornquist). Además, confirma que la línea de la zanja se había interrumpido antes de llegar a Guaminí. En la mensura nº 24 de Adolfo Alsina (AHG, 1889) se representa 
el inicio de la zanja en las nacientes del arroyo Pul Grande, la ubicación de los fortines cercanos, las lagunas, arroyos y otros rasgos geográficos, así como la vista de las sierras de Ventana y Puan son tomadas como referencia para el establecimiento de mojones y límites entre los terrenos. En cambio, la mensura $\mathrm{n}^{\mathrm{o}} 53$ del año 1926 (AHG) ya no muestra como referencias ni el trazado de la zanja ni los fortines que hubo en la zona. Por otra parte, en la década de 1920 se construyó un fortín-museo en la orilla sur de la laguna Epecuén para evocar la campaña al desierto, en el lugar aproximado donde habría estado el fortín Centinela (mencionado como fortín viejo en la mensura ${ }^{\circ} 1$ de Puan en el año 1881, próximo al arroyo Pul Grande). En la actualidad esta obra se encuentra en ruinas. Con respecto a la comandancia General Belgrano, como Carhué era un punto importante para la ocupación debido a su posición estratégica, se desarrolló un sistema defensivo que aseguraba su inexpugnabilidad, a través de emplazar fortines a su alrededor que funcionaran como una malla protectora, cuyo fuego cruzado los protegía recíprocamente e impedía las incursiones indígenas (Thill y Puigdomenech, 2003). Es interesante señalar que el municipio lleva el nombre del ideólogo de la zanja y la ciudad cabecera también conservó este nombre hasta el año 1949, cuando el decreto provincial 20191 estipuló que se le restituyese el nombre de Carhué.

En el partido de Puan se edificaron varios fortines sobre la línea de la zanja en el lapso 1876-1877, la cual presenta la particularidad de estar representada por el paredón o parapeto de Alsina en su mayor parte, ya que no se había podido cavar la zanja debido a la dureza del suelo. Estos asentamientos militares son (de norte a sur): Comandancia Ayudante Escudero, fortín Mateo Martínez, Comandancia Sargento Segovia, fortines Legión Militar, Coronel Catalán, Justo Reyes (éste poseía la particularidad de presentar forma de estrella), Regimiento Primero y Coronel Ruiz. En este distrito se han realizado tareas de relevamiento, prospección y recolección de materiales en tres fortines próximos entre sí: Mateo Martínez, Sargento Segovia y Legión Militar; este último cuenta con antecedentes de estudios previos (Panizza y Devoto, 2018). Los elementos recuperados son compatibles con la cultura material esperable para el momento histórico estudiado (fragmentos de cerámica, de vidrio y de metal, restos óseos faunísticos, botones, cartuchos de plomo, entre otros; ver Panizza y Devoto, 2018). Estos asentamientos están incluidos en el tramo del paredón de Alsina construido desde el fortín Escudero hasta el fortín Catalán, al que se suma otro sector donde se conformó el paredón, desde el fortín de Justo Reyes hasta los fortines Regimiento $1^{\circ}$ y Coronel Ruiz. En el año 1968 aparecieron restos humanos en el casco urbano de la cabecera del distrito, estudiados en la Universidad del Sur, los cuales fueron atribuidos a un cementerio militar correspondiente a la Comandancia de Frontera que funcionó en dicha localidad (Rodríguez, 1968), y que figura como "cerritos del cementerio" en cartografía de la época (en el plano de "National Territories. Names of land-owners" de 1884, mencionado previamente; en la mensura $\mathrm{n}^{\circ} 1$ de Puan 1881 realizada por Eduardo Castex en 1881 y en el Plano de los terrenos de la sección tercera de la provincia de Buenos Aires hecho por el Departamento de ingenieros civiles de la República Argentina en 1882). Dicho lugar fue declarado lugar histórico por decreto $\mathrm{n}^{\circ} 6939$ del año 1968, se levantaron las réplicas de las columnas de los portales de la Comandancia, de un mangrullo y de la zanja de Alsina en la Plaza de la Patria. El mangrullo forma parte del Monumento al soldado desconocido de la "Campaña al Desierto", donde hay una urna depositada con los restos que se encontraron en la plaza.

En el partido de Saavedra, los fortines vinculados al paredón o parapeto de Alsina habrían sido los siguientes: Carlos Keen, General Domínguez, Melchor Romero, Coronel Marcos Paz, 17 de agosto, Salvador, Coronel Díaz, Comandancia Coronel Sandes o de los Chilenos, Capitán Rosas, 29 de agosto y Comandante Rivademar. En la orilla de la Laguna Salada de los Chilenos concluye el paredón, según Castex en la mensura $n^{\circ} 1$ de Puan, comenzando de nuevo en la margen opuesta. En la mensura $n^{\circ} 41$ de Saavedra (AHG) aparece señalizado el paredón y la zanja de Alsina que une el fortín 17 de agosto con el 
fortín Sandes y continúa hasta llegar a la Laguna de los Chilenos. En este conjunto, destaca el fortín y Comandancia Sandes, por su proximidad tanto a la laguna de los Chilenos como al camino o rastrillada de los Chilenos. Además, ha sido identificado el lugar correspondiente a un fortín conocido como Cevedio por la comunidad local, este nombre señala el apellido de los propietarios del terreno aproximadamente en 1940, y que habría sido el fortín Coronel Díaz.

Las mensuras (que fueron confeccionadas entre los seis a 18 años posteriores a la construcción de la zanja y fortines asociados) brindan numerosos datos en vinculación con la zanja, que recibe varias denominaciones en los escritos ("paredón de la línea de frontera", "paredón”, "zanja Alsina", "terraplén conocido por Zanja o Paredón Alsina”, “parapeto”, "paredón de Alsina”, "parapeto y zanja de la línea de fronteras"), y en relación con los elementos naturales (lagunas, arroyos, entre otros) y con otros elementos culturales del paisaje, que nos aportan datos en cuanto al poblamiento de la zona, como la línea telegráfica, la oficina del telégrafo, los caminos (a Fuerte Argentino, de Puan a Bahía Blanca, de los montes de Alfalfa, de Pigüé a la estación de Adolfo Alsina), las ruinas de los fortines, puestos, casas de negocios, estancias, poblaciones, y colonias entre otros (AHG, mensuras no 2, 19, 29, 30, 36 y 41 de Saavedra, Figura 3D).

En el partido de Tornquist se encuentra el extremo más austral de la Zanja de Alsina, que llega hasta el fortín Manuel Leo, sobre el río Sauce Chico. Se había proyectado continuar la zanja hacia el sur, pero no se llevó a cabo al considerarse que el río Sauce Chico funcionaba como un obstáculo natural. En esta zona del Sauce Chico la estrategia empleada fue inutilizar los pasos que presentaba este curso de agua, desde el Paso de los Chilenos hasta Manuel Leo, mediante el trazado de trechos aislados de zanja entre barraca y barranca (Alsina, 1877, p. 273). En el Plano de la sección XIX de tierras públicas y zanja de Alsina desde Fortín Argentino (en Tornquist) hasta Guaminí de 1883 se observa que la punta de la Zanja llega hasta el río Sauce Chico, frente al Fuerte Argentino, y se menciona el Parapeto de Alsina (Figura 3E). La Comandancia del Fuerte Argentino fue declarada Monumento Histórico Nacional por decreto $\mathrm{n}^{\mathrm{o}}$ 1792 del año 1968. Fue construido en 1876 por orden del general Cerri sobre las márgenes del río Sauce Chico, en él se conservan los restos del reducto que integró la línea de fortines, donde se estableció la comandancia de la división Sur. En la mensura no 67 del año 1900 (AHG) la "zanja antigua de frontera" aparece representada en un corto trecho, en su extremo final antes de cruzar el arroyo Sauce Chico frente al "antiguo fortín Fuerte Argentino", otros elementos señalizados son la Estancia Fuerte Argentino, el Paso del Chileno, los puestos, los potreros, los molinos, la línea del telégrafo nacional y el camino real de Carhué a Bahía Blanca.

Por último, es interesante resaltar el testimonio de quienes relevaron la zanja pocos años después de su construcción, los agrimensores Eduardo Castex, Esteban Royal y Tomás Dodds, entre otros. Castex en 1881 escribió:

Su figura es una línea sumamente quebrada debido sin duda a que para establecerla se ha ido buscando el terreno más apropiado y las lagunas para colocar los fortines que, salvo uno que otro, están todos contra la zanja en la parte de adentro. Esta zanja, en la parte que limita el terreno que he medido, es poco honda en jeneral y tiene en su orilla Este un parapeto o paredón de más de un metro de ancho por dos de alto conocido bajo el nombre de pared o paredón entre los que frecuentan esos parajes (AHG, mensura $n^{\circ} 1$ de Puan foja 10 cara posterior).

Royal en el año 1894 dejó asentado:

La Zanja de Alsina y los fortines asociados en los sectores centro y sur del área F. Oliva y M.C. PanizZa ecotonal húmedo seca pampeana 
El paredón constituye una línea recta, indeleble y cuya existencia a pesar de los años que pasaron desde su ejecución, es visibilísima y representa hoy un límite natura importante por los puntos de relacionamiento, fijos que ofrece con los ángulos que forma en sus desvíos. (AHG, mensura $\mathrm{n}^{\mathrm{o}} 36$ de Saavedra foja 2 cara anterior).

Ese mismo año, Dodds destaca el error cometido por otro profesional debido al "mal relevamiento hecho anteriormente del paredón de Alsina" (AHG, mensura $\mathrm{n}^{\circ} 37$ de Saavedra cara posterior de la foja 3). Todavía en el año 1902 aparece mencionado en las diligencias de mensuras como "parapeto de la zanja de fronteras", constituyendo un rasgo relevante del paisaje a partir del cual se referencian las medidas en la demarcación de los terrenos (AHG, mensura $n^{\circ} 48$ de Rivadavia).

La ejecución de esta obra se adaptó a la diferencia de los espacios geográficos que abarcaba de norte a sur. Ya desde su diseño planteaba la diferencia entre tierras blandas y duras para proponer diversas estrategias sobre la construcción de la zanja y paredón de acuerdo a los rasgos del terreno, pero también se aprecia la versatilidad de las estrategias implementadas, al cambiar lo proyectado y aprovechar los rasgos naturales del paisaje para integrarlos en el proyecto (como sucede en el área de las Encadenadas o en el valle del río Sauce Chico en su extremo sur).

\section{Consideraciones finales}

Para finalizar, se destaca el carácter de obra monumental que tuvo el proyecto de Alsina, debido a la modificación en el paisaje del ecotono bonaerense que trajo aparejada su implementación y la gran extensión en kilómetros que alcanzó (aunque no haya sido la totalidad de la proyectada inicialmente). Los datos provenientes de fuentes históricas y evidencias geomorfológicas indicarían una mayor aridez de la zona pampeana hasta fines del siglo XIX (Politis, 1984; Deschamps et al., 2003; 2014; Tonni, 2017), de este rasgo del paisaje derivaría el nombre de la "conquista del desierto" que, en realidad, fue una guerra por el territorio. Sin embargo, este término implica una construcción ideológica que no se limita solamente a características del paisaje, sino que se corresponde a una tradición en la cartografía occidental que promueve la denominación de terrae incognitae o "desiertos" para aquellos espacios desconocidos, susceptibles de ser dominados e incorporados(para un análisis más pormenorizado, ver Rodríguez, 2010). La gran longitud desplegada en el terreno, unida al costo material implicado (en dinero y en fuerza de trabajo) contrasta con el breve lapso de funcionamiento que tuvo la obra en sí de la zanja y los fortines asociados a esta avanzada. En cuanto a la cantidad de fortines asociados a la Zanja, algunos de los más importantes (que funcionaron como fuertes y comandancias) dieron origen a localidades actuales y se convirtieron en las cabeceras de distrito (como son los casos de Trenque Lauquen, Guaminí, Carhué, Puan).

La traza de la zanja de Alsina fue determinante no sólo por lo que significó en su momento para el avance territorial del Estado y su estrategia en contra de las poblaciones indígenas, sino porque tuvo efectos sobre la construcción del espacio que perduran hasta hoy: en cuanto a la división del terreno y la conformación de establecimientos agrícolas ganaderos (la zanja se constituyó en un elemento relevante y visible del paisaje que sirvió para dividir los campos de un lado y del otro); para la traza de las vías de circulación, como la ruta nacional $\mathrm{n}^{\mathrm{o}} 33$ y caminos vecinales; y con respecto al origen y desarrollo de las localidades más relevantes de la región, como ya ha sido mencionado previamente.

Otra característica relevante que se determinó en las tareas desarrolladas sobre el terreno, consiste en que tanto el trazado de la zanja y paredón de Alsina como los sitios de los fortines se encuentran fuer- 
temente afectados por las actividades agro-ganaderas y el trazado de caminos en el ámbito rural (Figura 4), y por las construcciones edilicias y la remoción de sedimentos en el ámbito urbano, dado que los principales núcleos poblacionales de la zona se han desarrollado sobre los antiguos asentamientos militares (Trenque Lauquen, Guaminí, Carhué, Puan).

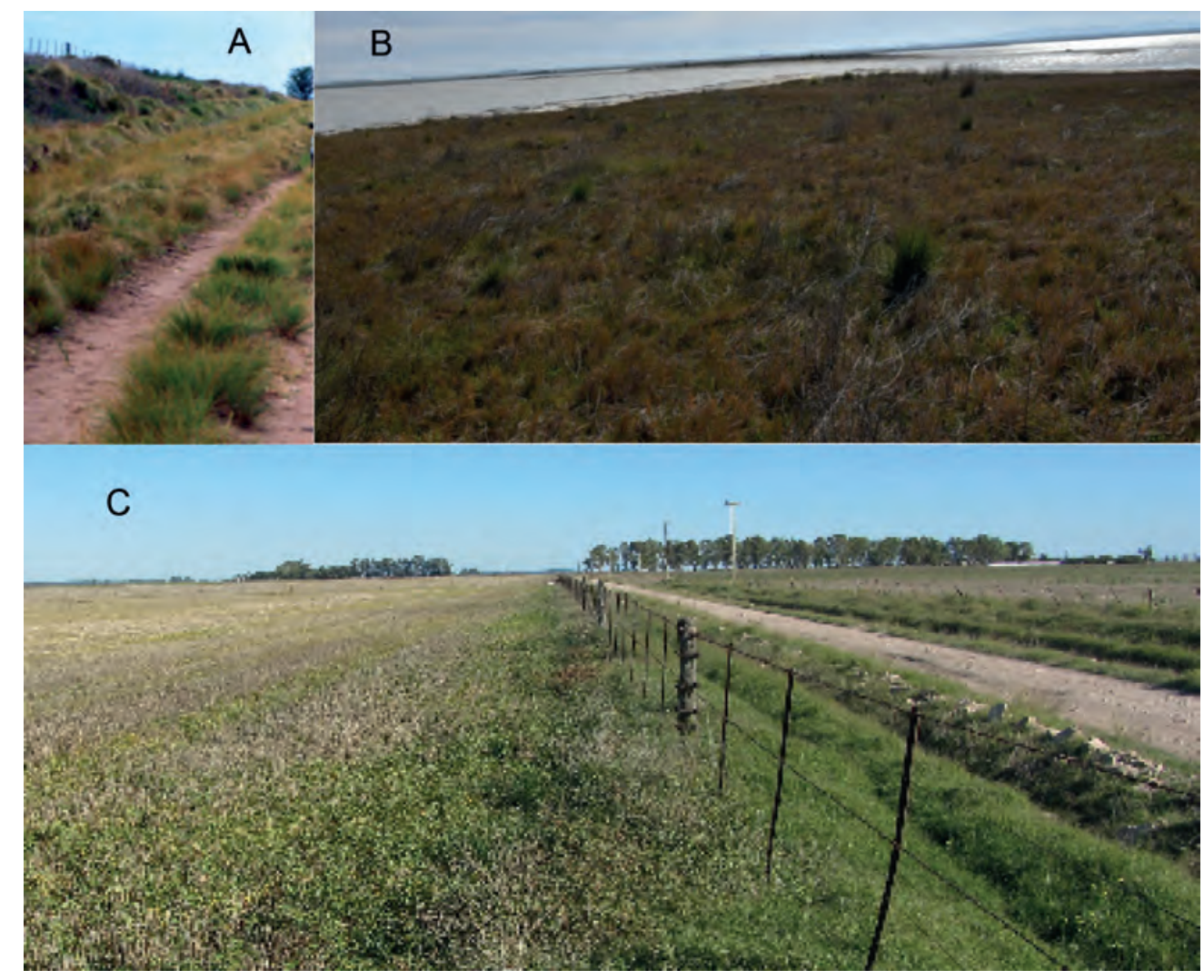

Figura 4.Algunos de los sectores relevados de la Zanja de Alsina. A) Partido de Trenque Lauquen. B) Partido de Saavedra. C) Partido de Puan. Se puede observar el impacto antrópico sobre los restos de la zanja, por la construcción de caminos y el tránsito vehicular, la instalación de alambrados y las actividades agrícola-ganaderas; al mismo tiempo que actúan procesos naturales, como la erosión eólica e hídrica (por los cambios en los niveles lagunares, inundaciones), entre otros.

Por último, debe destacarse que este lapso de la historia, centrado en el avance de la frontera estatal y la ocupación del territorio indígena, constituye un elemento fundamental en la construcción de las identidades regionales y los imaginarios de las comunidades locales, que se expresa a través de escudos, monumentos y discursos, entre otros dispositivos de visibilización. Por lo tanto, a partir de este trabajo se abren diversas líneas de investigación, que se abordarán en futuros estudios, entre las cuales pueden mencionarse la construcción social del espacio y su vinculación a la materialidad y la memoria, el motivo de la Zanja de Alsina en los discursos e imaginarios locales, su resignificación a través del tiempo; las réplicas y recreaciones de la zanja y los fortines asociados a esta línea de frontera, y su rol en la conformación de las distintas identidades en pugna dentro de las comunidades del área. 


\section{Agradecimientos}

A los dueños y administradores de las propiedades donde se encuentran los sitios arqueológicos, especialmente a Betty Brizzola de Puan y a Vivian Ballestrieri de Fuerte Argentino. Al personal del Ministerio de Gestión Cultural del Gobierno de la Provincia de Buenos Aires, por el apoyo logístico prestado. A los funcionarios municipales de los distritos involucrados, especialmente a Jorgelina Walter de Puan. Este trabajo se enmarca en el proyecto HUM 525 "Arqueología histórica en el área del Sistema Serrano de Ventania y su llanura adyacente", acreditado en la Universidad Nacional de Rosario; en la Beca Post-Doctoral CONICET de uno de los autores (MCP), y en las actividades desarrolladas desde el Centro de Estudios Arqueológicos Regionales (CEAR) de la Facultad de Humanidades y Artes (Universidad Nacional de Rosario) y desde el Laboratorio de Análisis Cerámicos (LAC) de la Facultad de Ciencias Naturales y Museo (Universidad Nacional de La Plata).

\section{Referencias bibliográficas}

ACADEMIA NACIONAL DE LA HISTORIA (1980). Congreso Nacional de Historia Sobre la Conquista del Desierto. Tomos I a IV. Buenos Aires: Academia Nacional de la Historia.

ALSINA, A. (1877). La nueva línea de fronteras: Memoria especial presentada al H. Congreso Nacional por el ministro de la guerra Dr. D. Adolfo Alsina. Imprenta del Porvenir, Buenos Aires.

ARCE, R. P. (1980) Las exploraciones y estudios que concurrieron al avance de Alsina: Actuación de científicos y técnicos argentinos y extranjeros: Ebelot, Wisocky, Csetz, Tobertson, etc. En Congreso Nacional de Historia sobre la conquista del desierto, Tomo IV, pp. 9-21. General Roca: Academia Nacional de la Historia.

BARBA, F. (1977). La zanja de Alsina, la ofensiva olvidada. En Actas del Tercer Congreso de Historia Argentina y Regional. Buenos Aires, Academia Nacional de Historia.

BARROS, Á. (1872) Fronteras y territorios federales de las Pampas del Sur. Buenos Aires: Imprenta, litografía y fundición de tipos a vapor.

BLENGINO, V. (2005). La Zanja de la Patagonia. Los nuevos conquistadores: militares, cientificos, sacerdotes y escritores. Fondo de Cultura Económica. Buenos Aires.

CACCIA, C. N. (2004).Historia de Intendente Alvear. Provincia de La Pampa. Córdoba: Comunicarte Editorial.

CASTILLO DE PARRILO, V. L. (1980). Reflexiones sobre Adolfo Alsina. La nueva línea de frontera y la ganadería. En Congreso Nacional de Historia sobre la conquista del desierto, Tomo I, pp. 277 285. General Roca: Academia Nacional de la Historia.

COMANDO GENERAL DEL EJÉRCITO, DIRECCIÓN DE ESTUDIOS HISTÓRICOS (1974) Política seguida con el aborigen. Tomo II (1820-1853), 3 volúmenes. Buenos Aires: Círculo Militar.

DEBENEDETTI, E. C. (1980). Conceptos vertidos por Zeballos sobre la Campaña de Alsina, 1876, a través del diario "La Prensa". En Congreso Nacional de Historia sobre la conquista del desierto, Tomo IV, pp. 321-336. General Roca: Academia Nacional de la Historia.

La Zanja de Alsina y los fortines asociados en los sectores centro y sur del área

F. Oliva y M.C. PANIZZA ecotonal húmedo seca pampeana

Páginas 59-80 
DEL RIO, W.; LENTON, D.; MUSANTE, M.; NAGY, M.; PAPAZIAN, A. Y PÉREZ, P. (2010). Discussing Indigenous Genocide in Argentina: Past, Present, and Consequences of Argentinean State Policies toward Native Peoples. Genocide Studies and Prevention 5, 138-159.

DEPARTAMENTO DE GUERRA Y MARINA (1878). Memoria presentada por el Ministro Secretario de Estado en el Departamento de Guerra y Marina al Honorable Congreso Nacional en el año 1878. Buenos Aires: Imprenta Moreno.

DESCHAMPS, J.; OTERO, O.; Y TONNI, E. P. (2003). Cambio climático en la pampa bonaerense: las precipitaciones desde los siglos XVIII al XX. Documento de Trabajo N 109 , Universidad de Belgrano. $20 \mathrm{pp}$.

DESCHAMPS, J.; OTERO, O. Y TONNI, E. P. (2014). Las precipitaciones en el noreste de la región pampeana (Provincia de Buenos Aires, Argentina) entre 1745-1900. Una reconstrucción histórica. Documentos de Trabajo No 304. Departamento de Investigaciones. Universidad de Belgrano. 24 pp.

EBELOT, A. (1968). Recuerdos y relatos de la guerra de fronteras. Buenos Aires: Plus Ultra.

ETCHEGARAY DE AÑON SUÁREZ, M. (1978). Aspectos de la campaña del doctor Adolfo Alsina de 1876 a través de la prensa de la época. Trabajos y Comunicaciones, 23, 75-86. En Memoria Académica. Recuperado en: http://www.memoria.fahce.unlp.edu.ar/art_revistas/pr.1107/pr.1107.pdf

ESTÉVEZ, J. J. (2000). Historia Trenquelauquenche. Trenque Lauquen: Editorial Trenque Lauquen.

FERNÁNDEZ, A. (2017). La ley argentina de inmigración de 1876 y su contexto histórico. Almanack, (17), 51-85. Recuperado en: https://doi.org/10.1590/2236-463320171705

GAMBONI, O. D. (1994). Adolfo Alsina, Gobernador de la Provincia de Buenos Aires y conquistador del desierto. Buenos Aires (La Plata): Universidad Católica de La Plata.

GARCÍA, P. A. (1969 [1810]). Diario del Viaje a Salinas Grandes. En De Angelis, P. (ed.); Colección de Obras y Documentos relativos a la Historia antigua y moderna de las Provincias del Río de la Plata, tomo IV: 295-391. Buenos Aires: Plus Ultra.

GARCÍA, P. A. (1969 [1822]) Diario de la Expedición de 1822 a los Campos del Sur de Buenos Aires, desde Morón hasta la Sierra de la Ventana. En De Angelis, P. (ed.); Colección de Obras y Documentos relativos a la Historia antigua y moderna de las Provincias del Río de la Plata, tomo IV: 393-671. Buenos Aires: Plus Ultra.

GARRETON, J. A. (1946) Escritos comunicaciones y discursos del coronel Juan Antonio Garretón publicados en la prensa de Buenos Aires, desde 1819 a 1852, con el diario de marchas de la expedición al desierto en 1833. Buenos Aires: Araujo.

GERTSNER, L. (2010). La línea de frontera entre "bárbaros" y "civilizados" en la Argentina del siglo XIX: el caso de la Zanja de Alsina. Una visión desde Google Earth y el aporte de los museos virtuales. Ar@cne. Revista electrónica de recursos en internet sobre Geografía y Ciencias Sociales No 138. Barcelona: Universidad de Barcelona. Recuperado en: http://www.ub.es/geocrit/aracne/ aracne-138.htm.

La Zanja de Alsina y los fortines asociados en los sectores centro y sur del área F. Oliva y M.C. PanizZa ecotonal húmedo seca pampeana 
GÓMEZ, R. A. (1980). Arquitectura y urbanismo en la Campaña del Desierto de 1876. En Congreso Nacional de Historia sobre la conquista del desierto, Tomo IV, pp. 403-419. General Roca: Academia Nacional de la Historia.

GONZÁLEZ, A. R. (1952a). Resucita el Avión los Secretos de Civilizaciones Milenarias, $1^{\text {a }}$ Parte, Revista Nacional de Aeronáutica, XII (128): 14-17.

GONZÁLEZ, A. R. (1952b). Resucita el Avión los Secretos de Civilizaciones Milenarias, $2^{\mathrm{a}}$ Parte, Revista Nacional de Aeronáutica, XII (129): 28-31.

HERNÁNDEZ, J. A. (1969 [1770]). Diario que el capitán D. J. A. Hernández ha hecho en la expedición contra los indios teguelches... en $1^{\circ}$ de octubre de 1770”. En De Angelis, P. (comp.), Colección de Obras y Documentos relativos a la Historia antigua y moderna de las Provincias del Río de la Plata, tomo IV: 107-45. Buenos Aires, Plus Ultra.

LANDA, C. G.; PINEAU, V. G.; COLL, L. V. J.; ALFAYATE, E.; CARETTI, M. F.; DOVAL, J.; REARTE, A.; ANDRADE, A. Y MONTANARI, E. (2017). Análisis espacial de la Zanja de Alsina en la Provincia de La Pampa, Argentina (1876-1879): Un abordaje interdisciplinario entre la Arqueología y la Geografía. Huellas 21; 2: 99-120. Universidad Nacional de La Pampa. Facultad de Ciencias Humanas. Instituto de Geografía.

MAYO, F. J. (2003). Un titán del desierto. Gral. Conrado E. Villegas. Buenos Aires: Cámara de Diputados de la Provincia de Buenos Aires.

MICHELUTTI, C. (2009). Cronología para la historia de Puan III. Buenos Aires: Dunken.

MIRAGLIA, M. (2010). Historia ambiental de la Cuenca de las Encadenadas del oeste de la provincia de Buenos Aires. Espacios, Geografía, pp. 28-35.

MONFERRÁN MONFERRÁN, E. E. (1958) Batalla de Currumalan-Chico. 20 de abril de 1877. Batalla de las Sierras de Pigüé. Buenos Aires: SUPRINT. 20 pp.

MONFERRÁN MONFERRÁN, E. E. (1962) El ejército de operaciones del Sud y la batalla del Pihué. Buenos Aires: Impr. del Congreso de la Nación.

MONTESARCHIO, L. A. (1990) Lagunas Encadenadas del Sudoeste de la Provincia de Buenos Aires: Descripción y análisis de sus características hidrográficas. Revista Universitaria de Geografía, $\mathrm{n}^{\circ}$ 4 (1 y 2), 159-178. Argentina.

NAGY, M. (2008). ¿No tan distintas? La construcción de la identidad bonaerense a través de los relatos históricos y la celebración de actos fundacionales en Trenque Lauquen y Pigüé. En Segundas Jornadas de Historia Regional del Oeste Bonaerense, Trenque Lauquen, 25 y 26 de abril.

NAGY, M. A. (2013). Los museos de la última frontera bonaerense y sus narrativas acerca de los pueblos indígenas. Revista Del Museo De Antropología, 6(1), 79-90. Recuperado en: https://revistas.unc. edu.ar/index.php/antropologia/article/view/5506/5952

NAVARRO FLORIA, P. (2013). Estanislao Zeballos. Episodios en los territorios del sur. Y Vanni Blengino. La zanja de la Patagonia. Los nuevos conquistadores: militares, científicos, sacerdotes, escri-

La Zanja de Alsina y los fortines asociados en los sectores centro y sur del área F. Oliva y M.C. PanizZa ecotonal húmedo seca pampeana 
tores. Quinto Sol, 10, 237-242. Recuperado en: https://cerac.unlpam.edu.ar/index.php/quintosol/ article/view/715/643

OlascoAgA, M. J. (1974). Estudio topográfico de La Pampa y Río Negro. Buenos Aires: Eudeba.

OLIVA, F. (2006). Usos y contextos de producción de elementos "simbólicos" del sur y oeste de la provincia de Buenos Aires (República Argentina). Revista de la Escuela de Antropología XII: 101116.

OLIVA, F. Y PANIZZA, M. C. (2015). Investigaciones Arqueológicas en el Área Ecotonal Húmeda Seca Pampeana. En: López, C. (coord.), Ciencia y tecnología 2015: divulgación de la producción cientifica y tecnológica de la UNR, pp. 1077-1083. UNR Editora. Universidad Nacional de Rosario. Formato electrónico.

OLIVA, F. Y PANIZZA, M. C. (2018). Arqueología histórica en el Área del Sistema Serrano de Ventania y su llanura adyacente. En: Orellano, E. (ed.), Ciencia y Tecnología 2017: divulgación de la producción cientfica y tecnológica de la UNR/Bulacio, L.; Pairoba, C.; coordinado por E. Orellano, L. Bulacio, C. Pairoba, P. Ponce de León, J. Molero; pp. 1335-1343. 1a ed. Rosario: UNR Editora. Editorial de la Universidad Nacional de Rosario.

ORGA, A. F. (2010). Por estas tierras... Recorrido geográfico e histórico de la ocupación de territorios en el partido de Rivadavia entre 1876 y 1910. América: edición propia.

PANETTIERI, J. (1984). La crisis de 1873. Buenos Aires: CEAL.

PANIZZA, M. C. Y DEVOTO, M. G. (2018). Arqueología histórica en el partido de Puan (provincia de Buenos Aires). En: Revista de Antropología del Museo de Entre Ríos 4 (1): 87-101.

PÉREZ, P. (2011). Historia y silencio: La Conquista del Desierto como genocidio no-narrado. Corpus, Vol 1, No 2. DOI: https://doi.org/10.4000/corpusarchivos. 1157

POLITIS, G. (1984). Climate variations during historical times in Eastern Buenos Aires Pampas, Argentina. Quaternary of South America and Antartic Peninsula, vol. 2: 133-159.

PRADO, J. M. Y L.V. GARCÍA LEDESMA (1980). La campaña y la zanja de Alsina en 1876 fue la base de apoyo y abastecimiento del rápido éxito de la realizada en 1879 por el general Roca hasta el Río Negro. En Congreso Nacional de Historia sobre la conquista del desierto, Tomo II, pp. 195-203. General Roca: Academia Nacional de la Historia.

PUEYRREDÓN, M. (1929) Escritos históricos del coronel Manuel A. Pueyrredón: Guerrero de la independencia argentina. Buenos Aires: Julio Suárez. 370 pp.

QUIJADA, M. (1999). La ciudadanización del "indio bárbaro". Políticas oficiales y oficiosas hacia la población de la pampa y la Patagonia, 1870-1920. Revista de Indias vol. LIX, nº 217, pp. 675-704. Madrid.

QUIJADA, M. (2003). ¿'Hijos de los barcos” o diversidad invisibilizada? La articulación de la población indígena en la construcción nacional argentina (siglo XIX). Historia Mexicana, vol. LIII, núm. 2, pp. 469-510. México.

La Zanja de Alsina y los fortines asociados en los sectores centro y sur del área F. Oliva y M.C. Panizza ecotonal húmedo seca pampeana 
RAMAYÓN, E.E. (1930). Guerreó en la Pampa por la civilización. Buenos Aires: Gir y Schaffner.

RODRÍGUEZ, A. (1968). Puan. Comandancia de frontera. Investigaciones y Ensayos, vol. 4: 89-102. Buenos Aires: Academia Nacional de la Historia.

RODRÍGUEZ, F. (2010). Un desierto para la Nación. La escritura del vacío. Buenos Aires: Eterna Cadencia.

RAMÍREZ JUÁREZ, E. (1946). La estupenda conquista. Buenos Aires: Julio Suárez.

SALDÍAS, A. (1892) Historia de la Confederación Argentina: Rozas y su época. Tomo II. Buenos Aires: F. Lajouane.

SÁNCHEZ, E. (1878). Biografía del Dr. Adolfo Alsina: Recopilación de sus discursos y escritos. Buenos Aires: Imprenta de La Tribuna.

SÁNCHEZ LABRADOR, J. (1936 [1772]). Los indios pampas, puelches, patagones. Buenos Aires: Viau y Zona.

SÁNCHEZ ZINNY, F. (2010). Diario La Nación (Buenos Aires), sábado 13 de marzo de 2010. Recuperado en: http://www.lanacion.com.ar/1242474-las-perdidas-cicatrices-de-la-zanja-de-alsina

TARUSELLI, G. (2005-2006). Las expediciones a Salinas: caravanas en la pampa colonial. El abastecimiento de sal a Buenos Aires (siglos XVII y XVIII). Quinto Sol, 9-10, pp. 125-149. DOI: $10.19137 /$ qS.v10i0.710

THILL, J. Y PUIGDOMENECH, J. (2003). Guardias, fuertes y fortines de la Frontera Sur. Historia, antecedentes y ubicación catastral. Tomos I y II. Buenos Aires: Editorial Edivern.

TOMASSINI, H. Y VECCHI, R. J. (2015). La "Zanja de Rosas" y el fortín "La Catalina”: Un acercamiento inicial a estructuras militares defensivas en Bahía Blanca (primera mitad del siglo XIX). En: V Jornadas de investigación en Humanidades, vol. 4, pp. 51-58. Bahía Blanca, Argentina. Recuperado en: http://www.jornadasinvhum.uns.edu.ar/files/5JIeHVol04.pdf

TONNI, E. P. (2017). Cambios climáticos en la región pampeana oriental durante los últimos 1000 años. Una síntesis con énfasis en la información zoogeográfica. Rev. del Museo de La Plata, Vol. 2, Núm. 1: $1-11$.

VEZUB, J. E. (2011). 1879 - 1979: Genocidio indígena, historiografía y dictadura. Corpus, Vol 1, No 2. DOI: https://doi.org/10.4000/corpusarchivos.1165.

WALTHER, J. C. (1980). La conquista del desierto. Buenos Aires: Eudeba.

YABEN, J. (1938-1940). Biografías argentinas y sudamericanas. Buenos Aires: Metrópolis.

ZIZUR, P. (1972 [1786]). Diario de una expedición a Salinas emprendida por orden del Marqués de Loreto Virrey de Buenos Aires en 1786 por Don Pablo Zizur Alferez de fragata, y primer piloto de la real armada. En De Angelis, P. (comp.), Colección de obras y documentos relativos a la historia antigua y moderna de las Provincias del Río de la Plata, tomo VIII: 431-479. Buenos Aires: Editorial Plus Ultra. 


\section{Cartografía consultada}

Carta topográfica de la República Argentina, Hoja 3563-27-4 San Mauricio, levantada en año 1952. Instituto Geográfico Militar.

MELCHERT, F.1875. Carta topográfica de la pampa y de la línea de defensa (actual y proyectada) contra los indios. Sociedad Anónima, Buenos Aires.

Mensuras $\mathrm{n}^{\mathrm{o}} 1,2,3,4,13,18,23,24,25,27,33,34,35,36,44,45,46$ y 48 del partido de Rivadavia, $\mathrm{n}^{\circ}$ 4, 7, 16, 21, 32, 40, 42, 45, 47, 85, 89, 104 y 134 del partido de Trenque Lauquen, $n^{\circ}$ 8, 17, 21, 24, 28, 29 , 31, 39, 48, 56, 61, 66, 75, 76, 86 y 102 del partido de Guaminí, n 2, 4, 7, 13, 17, 24, 50 y 53 del partido de Adolfo Alsina; $n^{\circ}$ 1, 20, 30, 61 y 64 del partido de Puan; $n^{\circ}$ 1, 2, 3, 7, 19, 29, 30, 36, 37, 38 y 41 del partido de Saavedra; $n^{\circ}$ 14, 21, 44, 54, 67 y 73 del partido de Tornquist; mensura $n^{\circ} 127$ de Bahía Blanca y $\mathrm{n}^{\mathrm{o}} 35$ de Villarino; depositadas en el Archivo Histórico de Geodesia (AHG) del Ministerio de Obras Públicas de la Provincia de Buenos Aires.

Plano 3115-28-1. National Territories. Names of land-owners. Archivo Histórico de Geodesia (AHG) del Ministerio de Obras Públicas de la Provincia de Buenos Aires.

Plano General de la Nueva Línea de Fronteras sobre La Pampa realizado por el Sargento Mayor Jordán Wysocki en el año 1877.

Plano de la Sección XIX. 1881. Archivo Histórico de Geodesia (AHG) del Ministerio de Obras Públicas de la Provincia de Buenos Aires, signatura 725-29-2.

Plano de los terrenos de la sección segunda de la provincia de Buenos Aires. Departamento de ingenieros civiles de la República Argentina 1881. Archivo Histórico de Geodesia (AHG) del Ministerio de Obras Públicas de la Provincia de Buenos Aires, signatura 630-27-4.

Plano de los terrenos de la sección tercera de la provincia de Buenos Aires. Departamento de ingenieros civiles de la República Argentina 1882. Archivo Histórico de Geodesia (AHG) del Ministerio de Obras Públicas de la Provincia de Buenos Aires, signatura 632-27-4.

Plano de los terrenos de la sección cuarta de la provincia de Buenos Aires. Departamento de ingenieros civiles de la República Argentina 1882. Archivo Histórico de Geodesia (AHG) del Ministerio de Obras Públicas de la Provincia de Buenos Aires, signatura 631-27-4.

WYSOCKI, J. (1877). Planos de la Nueva Línea de Fronteras sobre La Pampa (construidos por orden del Exmo. Señor Ministro de Guerra y Marina, General Don Adolfo Alsina). Buenos Aires: Imprenta y Litografía de A. Larsch.

ZIZUR, P. (1786a). Carta plana que comprende la demarcación del camino desde la Guardia de Luján hasta la Laguna conocida bajo el nombre de Salinas. Cartografía ARC.009-13-001. Biblioteca Nacional (Brasil). Recuperado en:

http://objdigital.bn.br/acervo digital/div cartografia/cart531966/cart531966.html

http://objdigital.bn.br/acervo_digital/div_cartografia/cart531966/cart531966.jpg

ZIZUR, P. (1786b). Carta (plana) que comprende la demarcación del camino desde la Guardia de Luján, hasta la Laguna conocida bajo el nombre de Salinas. Cartografía ARC.009-13-009. Biblioteca Nacional (Brasil). Recuperado en:

http://objdigital.bn.br/acervo_digital/div_cartografia/cart531970/cart531970.html http://objdigital.bn.br/acervo_digital/div_cartografia/cart531970/cart531970.jpg

Recibido: 10 de Junio 2020

Aceptado: 22 de Junio 2020

La Zanja de Alsina y los fortines asociados en los sectores centro y sur del área

F. Oliva y M.C. PanizZa ecotonal húmedo seca pampeana

Páginas 59-80 